\title{
National Security and the Accelerating Risk of Climate Change
}

American Association for the Advancement of Science 13 February 2015

Vice Admiral Lee Gunn, USN (Ret.) Vice Chair CNA Military Advisory Board Former Department of the Navy Inspector General 


\section{CNA's Leadership on Climate Change \& National Security}

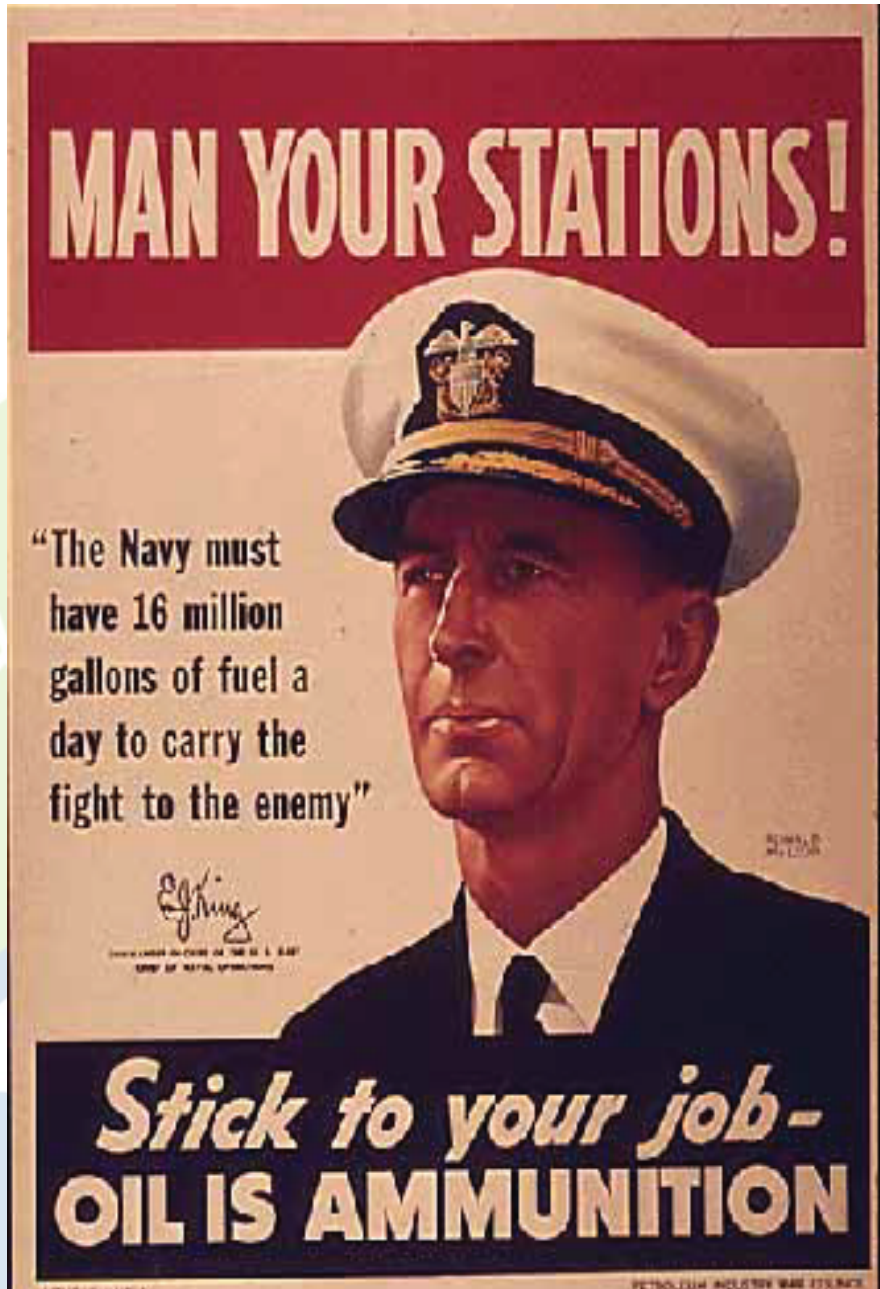

CNA -- Research organization providing in-depth analysis and solutions for government leaders

MAB -- 2007-2014 Over 30 Members (Rotational)

- General Gordon Sullivan, USA (Ret)

- General James Conway, USMC (Ret)

- Admiral "Skip" Bowman, USN (Ret)

- General Paul Kern, USA (Ret)

- General "Chuck". Wald, USAF (Ret)

- General Ron Keys, USAF (Ret)

- Vice Admiral Lee Gunn, USN (Ret)

- Rear Admiral Dave Titley, USN (Ret)

- General Don Hoffman, USAF (Ret.)

- Vice Admiral Ann Rondeau, USN (Ret.)

- Sherri Goodman 


\section{National Security and the Threat of Climate Change}

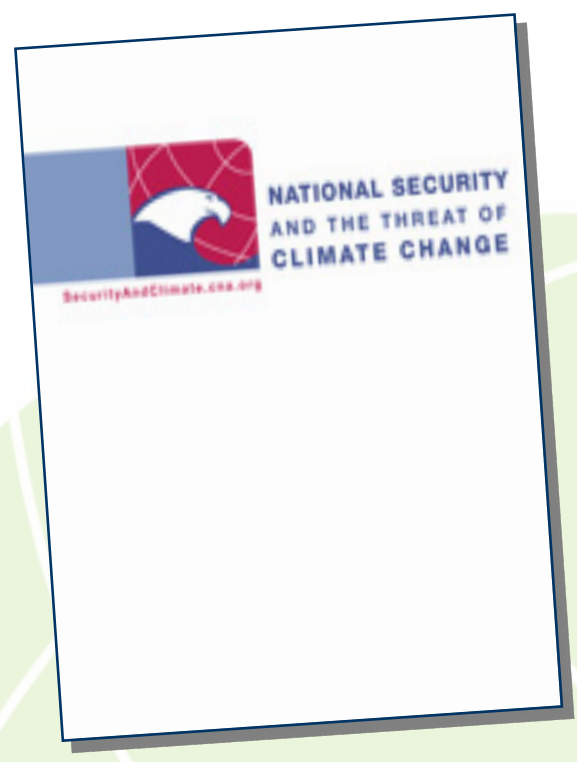

National Security and the Threat of Climate Change (2007)
- Climate change is a threat multiplier for instability in some of the most volatile regions of the world

- Projected climate change will add to tensions even in stable regions of the world

- Projected climate change poses a serious threat to America's national security

- Climate change, national security, and energy dependence are a related set of global challenges 


\section{National Security \& the Accelerating Risk of Climate Change}

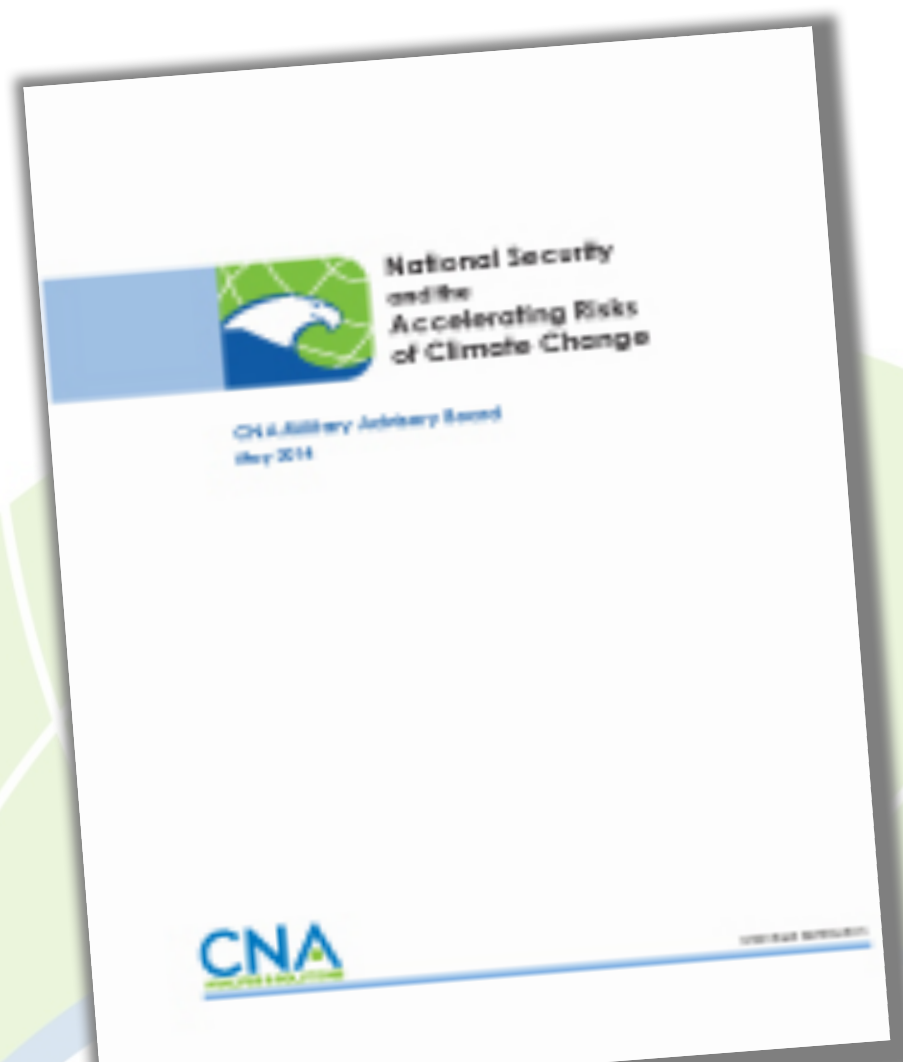

National Security and the Accelerating Risk of Climate Change (2014)

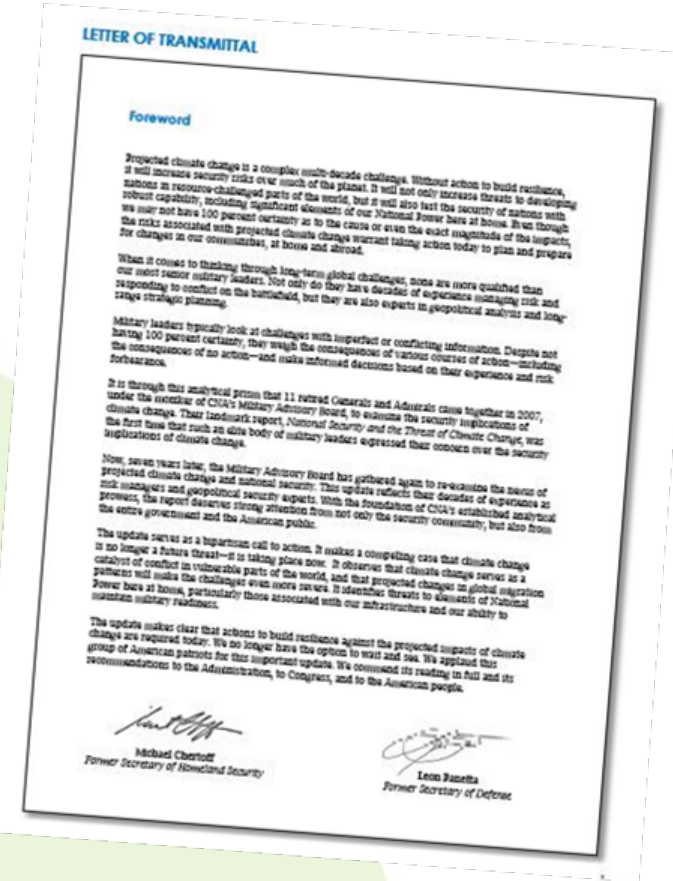

"The update serves as a bipartisan call to action. It makes a compelling case that climate change is no longer a future threat-it is taking place now... The update makes clear that actions to build resilience against the projected impacts of climate change are required today. We no longer have the option to wait and see....

We commend its reading in full and its recommendations to the Administration, to Congress, and to the American people."

Michael Chertoff

Former Secretary of Homeland Security

\section{Leon Panetta}

Former Secretary of Defense 
- We now observe that climate change risks are accelerating

- In some areas climate change is serving as a Catalyst for Conflict

- Climate change is happening today

- it's no longer a future threat

- Action is required today

- it's no longer an option to wait and see 


\section{International Implications of Climate Change}

1) Climate change is now a catalyst of conflict

i.e. Arab Spring, Syria, Mali

2) Rate of Change is accelerating, especially in the Arctic

3) Scientists' views are coalescing around causes and predictions

4) Population has grown by more than half a billion people and people and our "things" are more vulnerable

a. Urban area populations and valuable low lying areas

b. Water-food-energy nexus becoming more of a concern

5) Security landscape is more complex

a. Moving away from the Westphalia nation state

b. Increasing international interdependence and vulnerability to cascading effects across regions 


\section{More Vulnerable Populations}

\section{World's largest urban areas sit along coasts}

15 of 20 largest urban areas are near the coast, 14 of 20 largest urban areas are in Asia

An urban area is defined as a continuously buit up land mass of urban development than

is within a labor market (metropoittan area or metropolitan region) and has no rural land
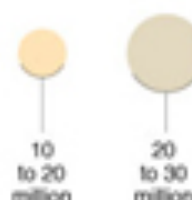

$10 \quad 20$

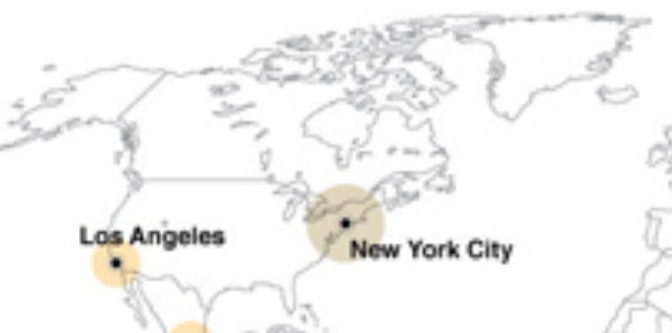

Mexico City

Sousce: Donograthia Wond utang nom Minch 2014

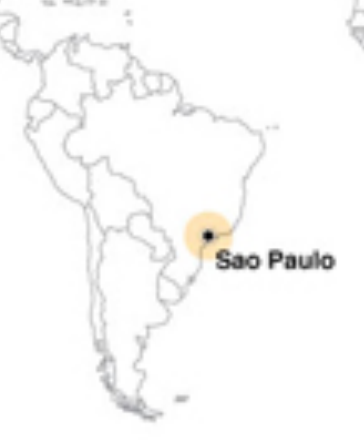

$10 \times 0$

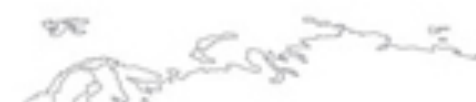

Moscow
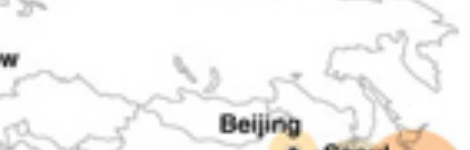

Beijing

Guangrto Sooul Tokyo

Cairo
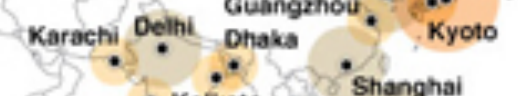
Shanghai More thanson

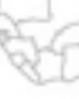
Mumbai - Kolikota Bangkok D Manila
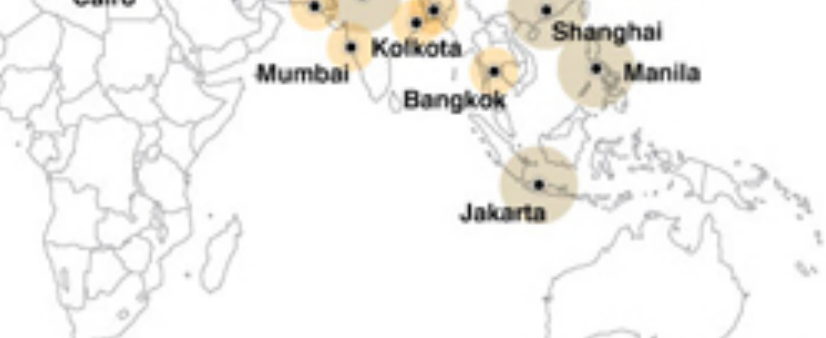

- More people live in cities than not

- 15 of top 20 urban areas are on coast

- 1 Billion people live in urban slums

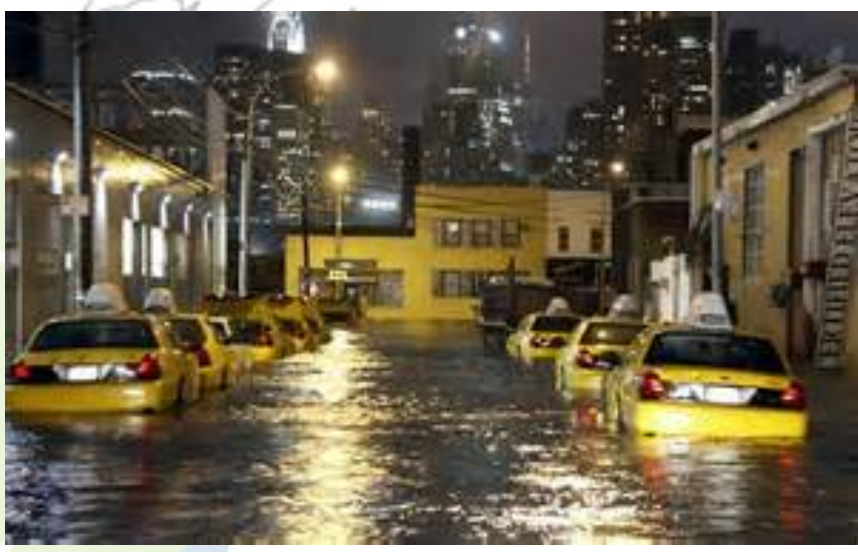

Urban Flooding Super Storm Sandy 


\section{Major Changes in the Arctic}

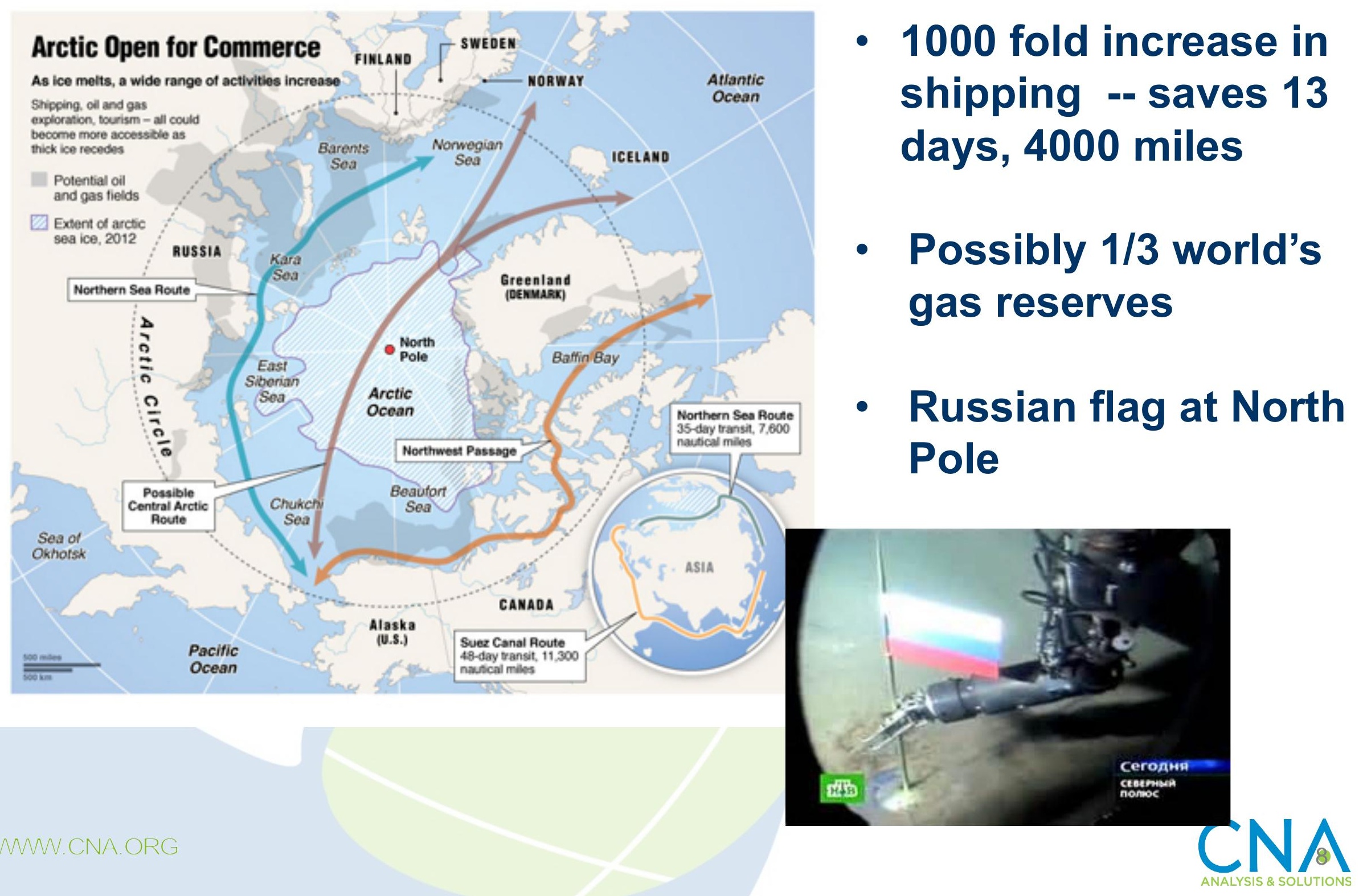




\section{Domestic Implications of Climate Change}

1) Increasing demands on America's military

a) Humanitarian assistance and disaster relief, both at home and abroad

b) Greater demand for responses to conflict

2) Threatens military training and readiness base resilience, access to ports and ranges

3) Threatens our economy, infrastructure and information systems, and social support systems, as well as first responders 


\section{Recommendations}

- The United States should take a leadership role in preparing the world for the projected impacts of climate change.

- Supported by national intelligence estimates, the U.S. military's Combatant Commanders should factor in the impacts of projected climate change across their full spectrum of planning and operations.

- The United States should accelerate and consolidate its efforts to prepare for increased access and military operations in the Arctic.

- Climate adaptation planning should consider the water-food-energy nexus to ensure comprehensive decision-making.

- The projected impacts of climate change should be integrated fully into the National Infrastructure Protection Plan and the Strategic National Risk Assessment.

- In addition to DOD's conducting comprehensive assessments of climate change on mission and operational resilience, the Department should develop, fund, and implement plans to adapt and place a greater emphasis on the projected impacts of climate change on both DOD facilities and associated community infrastructures. 


\section{Discussion}

\section{USA A A A , CO}
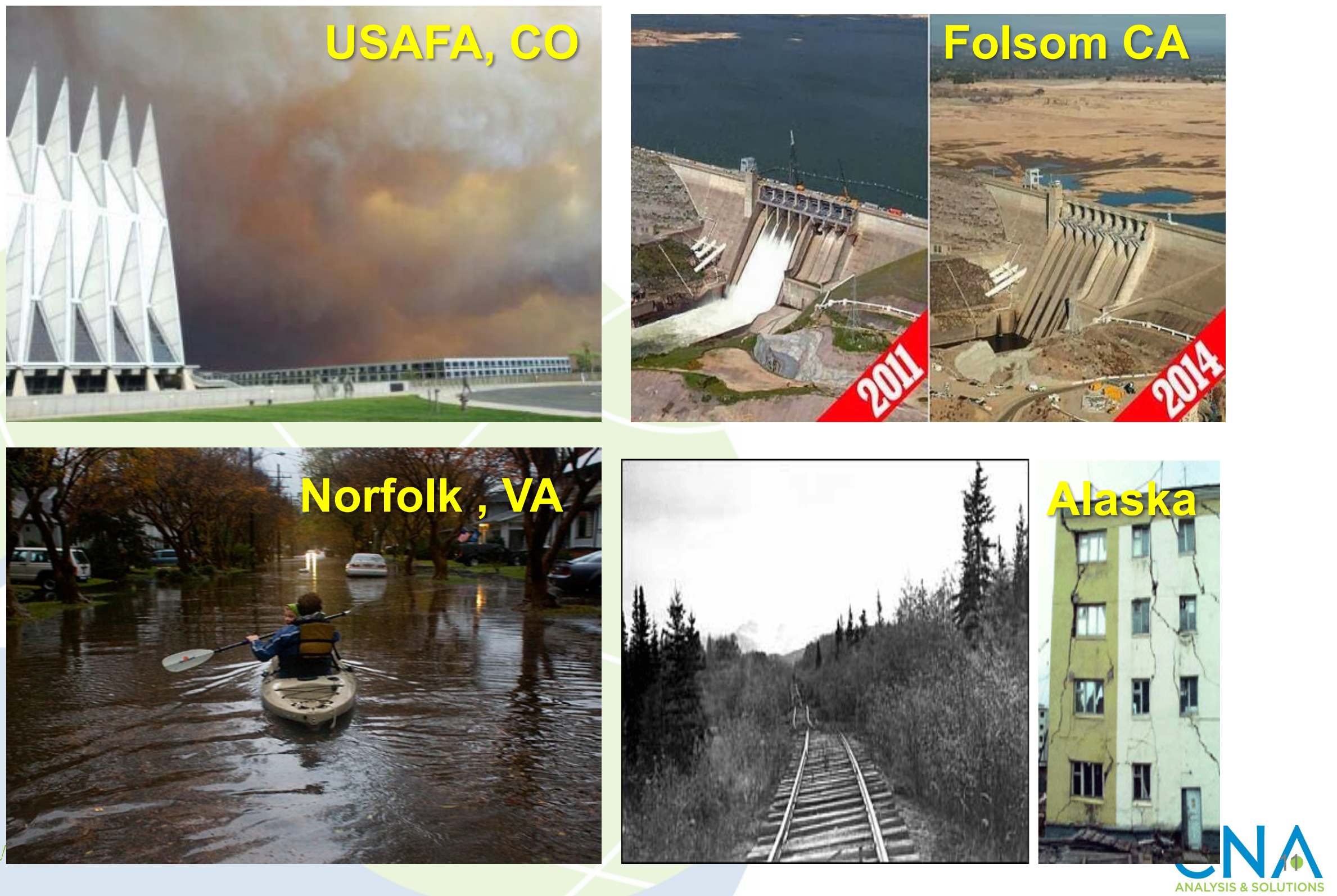